\title{
RELAÇÃO SOCIEDADE-NATUREZA NO PENSAMENTO GEOGRÁFICO: REFLEXÕES
} EPISTEMOLÓGICAS

\author{
Jovenildo Cardoso Rodrigues ${ }^{1}$ \\ Jondison Cardoso Rodrigues ${ }^{2}$
}

Resumo: Este ensaio busca tecer considerações epistemológicas acerca do debate da relação sociedade-natureza no pensamento geográfico. Para tanto, retoma-se às matrizes teóricoepistemológicas clássicas, a saber, as concepções kantiana, hegeliana e marxista, bem como a interlocução com perspectivas do pensamento geográfico contemporâneo de Quaini, Vitte e Moreira, enquanto possibilidade analítica para se pensar o objeto de estudo da geografia e a "natureza" como elemento processual de mediação, cuja potencialidade reflexiva vem sendo redefinida continuamente, como resultado do movimento de transformação da realidade. Dentro dessa perspectiva, no plano geral, a categoria natureza, enquanto totalidade em totalização, realiza-se a partir do engendramento da natureza como concepção e como produto da realização humana ao longo do tempo e do espaço. As particularidades imanentes ao movimento de transformação e ressignificação do termo natureza em Geografia configura-se como resultado do "choque epistêmico" entre antigas e novas perspectivas de pensamento que buscam, de um lado, conceber "artifícios interpretativos" para aplicá-lo ao real, e de outro, analisar a diversidade do real em suas múltiplas determinações, estabelecidas ao longo do espaço-tempo e do movimento relacional entre historicidade e práxis.

Palavras-chave: Epistemologia; Geografia; Relação Sociedade-Natureza.

\section{Society nature relation in geographical thought: epistemological reflections}

\begin{abstract}
This work makes epistemological considerations about the discussion of the relationship between society and nature in geographic thought. For this purpose, it takes to the theoretical-epistemological classical matrices, the Kantian, Hegelian and Marxist concepts as well as the dialogue with prospects of contemporary geographic thought of Quaini, Vitte and Moreira, while analytical ability to think object of study of geography and "nature" as a mediation procedural element whose reflective capability is being continually redefined as a result of the movement of reality transformation. Within this perspective, the nature category, while aggregation in whole, will be held from the gendering of nature as a concept and as a product of human achievement over time and space. The particularities inherent in the movement of transformation and redefinition of the term nature in Geography appears as a result of "epistemic shock" between old and new perspectives of thought that seek, on the one hand, to conceive "interpretive devices" to apply it to the real and also, to examine the diversity of the real in its multiple determinations established along the space-time and relational motion between historicity and praxis.
\end{abstract}

Keywords: Epistemology; Geography; Nature-Society Relation.

\footnotetext{
${ }^{1}$ Economista pela Universidade da Amazônia, Geógrafo pela Universidade Federal do Pará, Mestre em Planejamento do Desenvolvimento pelo Núcleo de Altos Estudos Amazônicos, Doutorando em Geografia pela Universidade Estadual Paulista Júlio de Mesquita Filho. Docente da Faculdade de Geografia e Cartografia da UFPA. E-mail: jovengeo@yahoo.com.br

${ }^{2}$ É Licenciado em Ciências Naturais - Habilitação em Química pela UFPA, Especialista em Educação Ambiental e Uso Sustentável dos Recursos Naturais, Mestre em Ciências Ambientais e Doutorando em Desenvolvimento Socioambiental pelo Núcleo de Altos Estudos Amazônicos. Bolsista do Doutorado do CNPQ.E-mail: jondisoncardosorodrigues@yahoo.com.br
} 


\section{INTRODUÇÃO}

O pensamento geográfico contemporâneo está profundamente associado a análises da relação sociedade-natureza, cujas matrizes de pensamento encontram-se assentadas em diferentes concepções teórico-epistemológicas do pensamento ocidental, principalmente do grego (PORTO-GONÇALVES, 2011). Tais perspectivas influenciaram, de maneira significativa, a construção do pensamento geográfico de Humboldt, Ritter, Brunhes, Vidal, Ratzel, Tricart e George (MOREIRA, 2011).

Do mundo grego antigo ao mundo medieval, do período iluminista à sociedade ocidental contemporânea, é possível evidenciar diversas interpretações a respeito do termo "natureza" e da "relação sociedade-natureza", que vão desde a condição de categoria ontológica abstrata até reflexões teórico-metodológicas cujas bases filosóficas remontam a perspectivas que articulam historicidade e teoria-prática, e que hoje contribuem na compreensão de algumas manifestações e contradições da produção capitalista do espaço. Considerando tal discussão, o objetivo do ensaio é tecer considerações epistemológicas acerca do debate da relação sociedade-natureza no pensamento geográfico. Para tanto, retomou-se às matrizes teórico-epistemológicas clássicas, a saber, as concepções kantiana, hegeliana e marxista, bem como a interlocução com algumas perspectivas do pensamento geográfico de Quiani, Vitte e Moreira, a respeito da relação sociedade-natureza, enquanto possibilidade analítica para se pensar o objeto de estudo da geografia.

Para a construção das referidas reflexões epistemológicas, o artigo foi subdividido em cinco momentos que se apresentam articulados, quais sejam: o primeiro caracteriza-se de forma breve (en passant) a origem e os significados do termo "natureza" no mundo grego antigo e na idade média; o segundo momento constitui-se retomada ao pensamento kantiano acerca da natureza, atentando para as possibilidades e limites desta perspectiva; o terceiro momento é marcado por uma abordagem de características importantes da construção Hegeliana acerca da categoria natureza; o quarto momento é marcado pela apreensão da noção de natureza no pensamento marxista; e finalmente, o quinto momento, constitui-se na tentativa de se pensar a relação sociedade-natureza a partir de diálogo com as abordagens de Quiani, Vitte e Moreira.

Com efeito, os diferentes significados que o termo "natureza" assume no decorrer do processo de formação da sociedade ocidental requer uma reflexão acerca de como se 
configurava a natureza no pensamento grego antigo e nas relações sociais, naquelas circunstâncias histórico-geográficas. A seguir serão delineadas algumas reflexões a esse respeito.

\section{Origens e significados da natureza}

A separação homem-natureza (cultura-natureza, história-natureza) é uma característica marcante e inerente ao pensamento da sociedade ocidental. Essa matriz filosófica se encontra principalmente na Grécia antiga, segundo a qual o universo (natureza) constituirse-ia como ser único, imutável, não caótico e imóvel (Tales, Permênides e Zenão) (RANGEL JUNIOR, 2006).

Tales, Permênides e Zenão são precursores da ideia de disjunção entre homem e natureza (RANGEL JUNIOR, 2006) e contribuidores do pensamento contemporâneo, sobretudo, do "mundo ocidental", já que como enfatiza Morin (2008, p.79): "[...] nós somos herdeiros deste pensamento dissociador [...]"; de divisão, de separação, e cuja natureza seria compreendida enquanto materialidade objetiva, que supostamente se contrapõe ao psíquico, ao anímico, ao espiritual, da Physis (PORTO-GONÇALVES, 2006a, 2006b; MORIN, 2003).

Para Bornheim (1985), a palavra physis indica aquilo que brota por si, num desabrochar que se manifesta neste desdobramento, apresentando-se como realidade totalizante. Segundo Porto-Gonçalves (2011), é no século V a.C. que se tem a construção de uma perspectiva geral da ideia de natureza. É notadamente com Platão e Aristóteles, segundo PortoGonçalves, que se começa a assistir a um desprezo e mudança da noção de natureza enquanto elemento natural, espiritual, psíquico, de característica totalizante, cuja perspectiva tendeu a ideia de separação entre homem e natureza (OLIVEIRA, 2002; VITTE; SPRINGER, 2010).

A interpretação aristotélico-platônica sobre natureza basilará os "dogmas" do cristianismo durante a idade média, pautada na separação entre espírito e matéria. Se por um lado Platão estabelecia uma oposição entre o plano da ideia, vista como perfeita e a realidade mundana, evidenciada com inferior, de maneira similar o cristianismo operará a sua própria leitura, opondo a perfeição de Deus à imperfeição do mundo material (PORTO-GONÇALVES, $2011 ; 2006 b)$. 
$\overline{\text { Todavia, é com Descartes que essa oposição homem-natureza, mente e corpo, espírito- }}$ matéria, sujeito-objeto tornar-se-á mais densa, constituindo-se como centro do pensamento moderno e contemporâneo (MOREIRA, 2004, 2006; VITTE, 2007a). A esse respeito, dois aspectos da filosofia cartesiana, aqui expressos, vão marcar a modernidade, quais sejam: 1) o caráter pragmático que o conhecimento adquire enquanto elemento útil para a vida, compreendendo a natureza como um recurso, um meio para se atingir um fim; e 2) o antropocentrismo, perspectiva em que o homem passa a ser visto como o centro do mundo, sujeito em relação ao objeto, à natureza (MOREIRA, 2003; 2006; 2011; PORTO-GONÇALVES, 2011; SOUZA; SUERTEGARAY, 2007).

O século XIX constituirá momento de triunfo desse pragmatismo, com a ciência e a técnica adquirindo um significado central na vida dos homens (SANTOS, 1996; MOREIRA, 1992; 2011). Nesse sentido, a natureza torna-se cada vez mais um objeto a ser possuído, dominado, subdividido e fragmentado (SANTOS, 1996). Qualquer tentativa de pensar o homem e a natureza de uma forma orgânica e integrada torna-se cada vez mais difícil, uma vez que tal divisão não se dá apenas no campo do pensamento, mas também na realidade objetiva construída pelos homens.

Com efeito, retomar alguns elementos e momentos da construção social da ideia de natureza faz-se fundamental, uma vez que, segundo Morin (1996) os fenômenos sociais não são/estão isolados no tempo, eles estão/são conexos e repletos de emergências complexas e que implicam em dinâmicas presentes e futuras, como, por exemplo, quando se pensa na divisão social e técnica do trabalho enquanto concreticidade da vida dos homens; e, no fortalecimento do processo de fragmentação, de dicotomização, enfim, de "separação" do homem em relação à natureza tanto no campo acadêmico, quanto no âmbito do pensamento geográfico.

\section{Kant: o método de conhecimento e a Natureza}

Estamos, todavia, sob o signo do neo-kantismo e forte influência hegemônica do positivismo. E é nestes termos que este "retorno aos fundadores" então se dá. (MOREIRA, 2011).

Se queremos encontrar os fundadores filosóficos da ciência geográfica no momento de sua construção entre o final do século passado e o início deste século [século XX], temos de buscá-los em Descartes, Kant, Darwin, Comte e os positivistas, mas também em Hegel e em Marx. Isso para nos limitarmos a uns poucos nomes (SANTOS, 2004, p.47-8) [sic]. 
A compreensão do pensamento geográfico contemporâneo enquanto ciência dotada de concepções analíticas pressupõe revisitar alguns constructos teóricos, concepções de mundo que exerceram influência significativa na construção e na redefinição do sujeito e do objeto da geografia. Sendo assim, torna-se inevitável um diálogo com os manuscritos filosóficos de I. Kant, considerado um dos fundadores da moderna geografia, da géographie scientifique [ou a science de la différenciation régionale de écorce terrestre (p.142), [...] une science des relations spatiales une science spatiale (p.146)] (SANGUIN, 1994).

Essa géographie scientifique norteava o pensamento de Kant, sobretudo porque este afirmava que a construção do conhecimento filosófico deveria basear-se em um novo método de transmissão de conhecimento, através de um pensamento que consistia na separação entre ciências empíricas (pautadas na experiência) e ciências racionais (pautadas nas leis da natureza) (KANT, 1982).

Segundo Quaini (1979), Kant promoveu a instauração, no ano de 1756, de um novo método de transmissão do conhecimento, baseado num pensamento que tendeu a separar ciências empíricas das ciências racionais, e na perceptions humaines du monde (SANGUIN, 1994).

A geografia faz parte, segundo Kant, das ciências empíricas, isto é, fundamentadas na experiência (distintas, portanto, das ciências racionais fundamentadas na razão) tendo como finalidade "a erudição real" (real porque os objetos da nossa experiência nos aparecem no espaço, um ao lado do outro, ou no tempo, um após o outro), a qual compreende em parte a descrição dos objetos: a descrição do mundo; em parte, a narração de suas mudanças: a história do mundo (QUAINI, 1979, p.27).

O conhecimento apareceria, então, fundamentalmente amparado, ou sobre aquilo que já existe, conforme as leis tidas como "necessárias", segundo as quais consistiria o verdadeiro conhecimento da natureza; ou sobre os seres que agem conforme as leis da liberdade, o que pressupõe pensar o "conhecimento do homem ou da antropologia". Assim, por intermédio de tais ciências (antropologia e geografia física) buscava-se antecipar a experiência futura. Neste sentido, uma pergunta se faz importante, qual seja: que método Kant atribuiu à geografia?

A esse respeito, Quaini (1979) afirma que o pensamento kantiano ressalta dois elementos importantes: 1) a descrição do mundo ou da terra, perspectiva que deveria referir-se à ideia do todo, do conjunto e reportar-se sempre à geografia como conhecimento geral da terra, como saber orgânico e sistemático; 2) este conjunto ou todo pode ser definido somente em relação ao homem, à práxis humana. Tais elementos estariam assentados na compreensão 
de que a Geografia permitiria o acesso à ordenação e categorização do mundo. De fato, "Kant distinguishes geography as the description of the whole world from topography as the description of single places and chorography as that of regions" (ELDEN, 2009, p.17).

A geografia em Kant apresenta-se como geografia física, segundo a qual o homem constituise enquanto efeito da natureza, de uma experiência sensível determinada (VITTE, 2007b), ou da reciprocidade intrínseca entre mente e natureza (LIVINGSTONE; HARRISON, 1981). Não obstante, a geografia física kantiana em nada tem a ver com a geografia física que se compreende atualmente, posto que a abordagem kantiana comportava vários ramos que transcendem a concepção atual de geografia física, a saber: uma geografia moral; uma geografia política e comercial; e, mesmo, uma geografia teológica. Dentro dessa perspectiva, o núcleo da teoria de Kant, portanto, consiste na separação entre ciências especulativas e ciências pragmáticas, entre razão e experiência, entre geografia e antropologia, entre história e natureza (KANT, 1999; QUAINI, 1979; SANGUIN, 1994; ELDEN, 2009).

Não se pode deixar de considerar tais concepções como "deterministas" ou "mecanicistas", no que diz respeito às relações homem-ambiente e providencialistas ou metafísicas, no que diz respeito ao plano histórico (QUAINI, 1979; ELDEN, 2009; VITTE, 2007b; VITTE; SILVERIA, 2009), já que para Saguin (1994, p.141) "la géographie kantienne est clairement définie comme une science empirique mais il agit un empirisme régionalement appliqué".

Com efeito, apesar de Kant contribuir na compreensão da inseparabilidade de seres humanos do mundo, e esses em relação com a terra, a natureza e outros seres humanos (ELDEN, 2009), a concepção de natureza em Kant é transcendental (existência da natureza, deve ser procurado para além da natureza natural, conforme Kant (2013)) e regulativa (VITTE, 2006a; 2006b; ARENDT, 1992).

Para Kant (1997), a natureza seria representada como arte, particularmente as suas formas, que conferem um status ao conceito de finalidade e que procuram unir o juízo estético ao teleológico, além de resquícios metafísicos (KANT, 2000). Isso se refletiu na ideia de natureza que é atravessada pela Geografia física, isto é, no estudo da natureza (na descrição da natureza). Assim, a geografia nasce entre teologia da natureza e a estética (VITTE, 2006a; 2007b; 2008), mediada pela contemplação (VITTE, 2006b). Tal perspectiva implica, de certa forma, na própria noção de espaço enquanto uma representação a priori, fundamento dos fenômenos externos, que é intuição impura (SANTOS, 2004). Segundo Vitte (2008), a natureza Kantiana é concebida como um mero ordenamento empírico de fenômenos e, o espaço, como um, a priori, intuitivo e sem relação com o empírico. 
Ainda para Vitte (2008), a partir da influência da estética kantiana, a Geografia nascerá como sendo a representante de uma nova poiesis no mundo, "[...] uma ciência empírica da natureza, muito embora procure trabalhar com o nível de integração na visão do mundo [...]" (VITTE, 2006, p.15), nascida a partir da relação dialética entre a natureza e a arte, cujos representantes são Goethe e Alexander Von Humboldt (VITTE, 2008).

Kant promove abordagem relacional entre natureza e cultura, embasada numa perspectiva que considera a natureza: a) como experiência sensível; b) a história como uma manifestação múltipla e infinita da vida e da humanidade; e, c) uma natureza concebida como coisa/objeto, substrato da história dos homens, portanto estruturada como totalidade universal (universalista), que unidimensionava a natureza.

Kant apresenta alguns elementos "inconsistentes" para pensar a noção de natureza dentre os quais se pode destacar: suas elucubrações acerca da natureza concebida como coisa/objeto, portanto, estruturada e não caótica; a compreensão da natureza enquanto totalidade universal (universalista) de caráter ontológico, transcendental e regulativa. Convém ressaltar que essas perspectivas encontram-se entranhadas na derme de um considerável número de pesquisadores, estudantes e professores de geografia, conforme Moreira (2006). Tais perspectivas tendem a contribuir para a construção de uma visão dogmática e reducionista, unidimensionando a natureza pensada enquanto um dado a priori (MORIN, 2008). Com efeito, em que pese às potencialidades das reflexões de natureza em Kant, a abordagem kantiana, restringiu-se à construção de uma perspectiva ontológica de natureza que negligenciou a relação social entre humanos e não humanos, uma totalidade complexa, uma amálgama ecossistêmico da história-social construída.

\section{A "natureza" na abordagem hegeliana}

Hegel tenta désontologiser, isto é, fazer um esforço para expor o processo que parece congelado (QUENTIN, 2006), como a concepção kantiana de natureza, em particular, a separação entre natureza e história, entre o homem como ser natural e o homem como sujeito da história (QUAINI, 1979), entre natureza e espírito (MOREIRA, 2006). Hegel "radicaliza esta reflexão ao atribuir à natureza a ideia de que esta se alienou na matéria" (MOREIRA, 2006, p.65), isto é, natureza é em sua essência "self-alienated Spirit" (FOSTER; BURKETT, 2000). No entanto, essa compreensão está imersa na autoprodução do homem como um processo, como resultado de seu próprio trabalho, entendido enquanto mediação 
do homem com a natureza ao longo do processo histórico (HEGEL, 1961). A essência do sentido de "trabalho" em Hegel é capturada de modo unilateral como "trabalho espiritual abstrato" (HEGEL, 1992), isto é, como atividade do espírito de autoconsciência (MARX, 2004; 2010).

Ainda segundo Hegel (1961), a história universal é a realização do espírito, da ideia do espírito enquanto ele se mostra na realidade, como série de formações exteriores. O espírito do mundo realizar-se-iam nos diversos espíritos dos povos (povos cósmico-históricos), os quais estão separados no espaço e no tempo e sofrem a influência da situação natureza (HEGEL, 1992), estabelecendo uma relação do espiritual com o natural (QUAINI, 1979). Hegel compreende que a exterioridade das relações humanas são ao mesmo tempo, definidas como formação histórica (ou espiritual), e como formação natural (HEGEL, 1992; 2001). Assim, Hegel recupera e utiliza o postulado da correspondência entre estrutura física do ambiente e o "caráter do povo".

Para Hegel, coexistem relações inversas entre dependência frente à natureza e à civilização, ao longo da história, compreendida enquanto processo de libertação progressiva dos povos civis frente às condições dos próprios ambientes naturais, que passam a ter um peso cada vez maior (QUAINI, 1979; MARX, 2010; CHATELET, 1989). Hegel interpreta tal processo de libertação do homem frente à natureza em termos de relação dialética (HEGEL, 1982).

\footnotetext{
De fato [...] a propósito das relações homem-natureza: todo progresso evolutivo implica numa reflexão espiritual em si, contra a natureza; é um particularizar-se do espiritual em si contra esta sua qualidade imediata, que é justamente a natureza. Com este particularizar-se coincide o próprio momento da naturalidade, justamente enquanto esta é uma particularização: nasce a antítese entre o espiritual e o exterior (QUAINI, 1979, p.32).
}

O núcleo do debate hegeliano consistiria numa abordagem da dialética do espaço enquanto método para instituir as correlações entre estruturas geográficas e modos de vida dos povos, pois “pour Hegel, l'espace constitue le premier moment de la nature, mais ce n'en est qu'un moment" (QUENTIN, 2006, p.544), cujas particularidades manifestam-se em uma dialética que marca seu caráter fundamentalmente relacional (Op.cit). A esse respeito, Antunes (2005, p.63) afirma que para Hegel: "A primeira condição para que o homem se desenvolva enquanto indivíduo é sua separação com relação à natureza. Ao opor-se à natureza, o homem se descobriria enquanto ser racional e não apenas enquanto imediatidade natural". O contexto natural ou o fundamento geográfico da história universal (inserido na obra, $A$ Razão na História: Introdução à Filosofia da História Universal), concebido por Hegel enfatiza 
que: "Logo que o homem surge como homem, põe-se em oposição à natureza; só assim se torna homem" (HEGEL, 1995, p.180). A natureza para Hegel, portanto, segundo Pereira (2006), seria uma objetivação do espírito, e o conhecimento geográfico nesse contexto assumiria um caráter secundário pela relevância menor da realidade empírica.

A dialética enquanto unidade de opostos em Hegel demonstra um caráter regressivo e mistificador, uma vez que tal unidade constitui-se enquanto unidade do pensamento, ideia dialética do trabalho humano (dialética do trabalho espiritual). A esse respeito, para Chatelet (1989), a noção hegeliana de geografia estava associada, de maneira recorrente, às “ingenuidades e banalidades" (CHATELET, 1989, p.45):

[...] [para] Hegel, a geografia como tal pertence à história, isto é, a esta odisseia, a este vir-a-ser dramático dos povos ao longo do qual cada um dentre eles, encarnando, na sua civilização material, na sua legislação, nas suas estruturas espirituais, uma figura do espírito, constitui no seu tempo uma etapa no percurso da humanidade, em busca de sua completa realização. A geografia não é uma ciência como o são a mecânica ou a geologia; ela é um elemento- o elemento de base, no sentido material do termo, desta fenomenologia plenamente cumprida, totalmente racional, que é a história dos povos, das nações, dos Estados. Dizer que ela é fenomenológica, significa que ela é descritiva, mas seria um grave erro de leitura tomar este qualificativo de forma pejorativa. Esta descrição dada ao nível em que ela se situa, e total percepção da essência. Em outras palavras, ela é a apresentação do que há de essencial no habitat, a paisagem - no sentido forte com que esta implica em técnicas, em relações interindividuais, em imaginário - onde nascem, se desenvolvem e morrem (ou adormecem) as culturas que balizaram, por sua atividade original, o impulso sangrento e glorioso do homem (CHATELET, 1989, p.47-8).

Com efeito, convém ressaltar que tanto a dialética do espírito quanto a geografia em Hegel apresentam uma história nitidamente eurocêntrica (DUDLEY, 2009; LUTTER, 2009), justificada a partir de uma base geográfica e caracterizada por um processo histórico unidirecional em que as diversas fases históricas ou formações histórico-naturais são os momentos necessários da progressiva realização do espírito, que Hegel considera concluída na sociedade germano cristã do século XIX.

\section{O pensamento marxista e a natureza}

A construção do pensamento marxista sobre natureza embasou-se na abordagem hegeliana (organic and inorganic nature) (FOSTER; BURKETT, 2000) como ponto de partida para avançar rumo a uma perspectiva que pudesse analisar a natureza da produção capitalista. Partindo da concepção hegeliana segundo a qual a atividade humana em sua relação com a 
natureza, mediada pelo trabalho abstrato (mental) é sempre atividade de pensamento e este se encontra diretamente interligado com a linguagem da vida real (LUTHER, 2009). Marx propôs a inversão da construção do pensamento hegeliano, rumo a uma perspectiva que considerasse a relação sociedade e natureza mediada pelo trabalho material, compreendida enquanto constructo que resulta do movimento dialético entre historicidade e práxis social (MARX, 2011).

Com essa afirmação, Marx ataca a concepção ideológica da filosofia hegeliana, que disjunta as ideias e doutrinas, sem referência à produção histórica das relações sociais de produção e os interesses econômicos da sociedade (Ibid).

A natureza para Marx não pode ser concebida como algo exterior à sociedade, uma vez que aquela constitui produto histórico, sobretudo na relação entre o trabalho assalariado e o capital (MARX, 2011). É dentro dessa perspectiva que Marx

[...] instaura uma nova relação entre natureza e homem [...] justamente porque evita cair no monismo espiritualista de Hegel e no monismo naturalista do materialismo fisicalista ou do positivismo e determinismo, que se seguiram, coloca-se num plano decididamente humanista e integralmente historicista e, enquanto tal, não perde de vista nem a historicidade da natureza nem a naturalidade da história (QUAINI, 1979, p.43).

Marx, dentro de uma perspectiva geral, instaura um conjunto de reflexões que consideram a nova relação entre natureza e homem, ao conceber a relação entre o corpo orgânico do ser humano e o mundo inorgânico. Marx compreende o orgânico e o inorgânico como complementares e condicionados, pelas necessidades de subsistência dos seres humanos e sua capacidade por meio de trabalho social para transformar as condições "externas" da natureza em meios de satisfazer essas necessidades (FOSTER; BURKETT, 2000).

Ao invés de postular uma ruptura ontológica nítida entre os seres humanos e a natureza, Marx descreve as interligações materiais e intercâmbios dialéticos, associados ao fato de que a espécie humana, sendo similar às species-life em geral, encontra sua base objetiva na base natural fora de si mesma, condicionada na natureza, objetivo de sua existência. Neste sentido, o corpo orgânico da humanidade (como todas as espécies) inclui dentro de si as condições inorgânicas de sua existência, o que pode parecer, à primeira vista meras forças opostas, coisas "externas" (FOSTER; BURKETT, 2000). É nesse sentido que a crítica à abordagem marxista segundo a qual Marx compreenderia a "natureza" como sinônimo de mercadoria, como fonte de riquezas e que deve ser 'conquistada', dominada e subjugada aos interesses do "homem" é frágil e inconsistente (FOLADORI, 1997; FOSTER, 1998). 
Dessa maneira, a "segunda natureza" em Marx nada mais é do que um artifício linguístico que busca analisar as metamorfoses da natureza concebida enquanto totalidade em movimento perpétuo, no qual a ação humana é parte integrante da natureza enquanto produto e produtor dos meios de produção e reprodução da natureza. A ação humana, portanto, constituiria elemento capaz de reorganizar a sua relação com a natureza, em condições de liberdade humana, de desenvolvimento pleno das necessidades e potencialidades humanas, e uma unity with nature (FOSTER,1998).

A natureza constitui ponto importante nas reflexões marxistas, sobretudo porque este compreendia que a estruturação do modo capitalista de produção embasava-se primordialmente no estabelecimento de algumas condições essenciais, sem as quais não seria possível a construção da dominação capitalista, quais sejam: o estabelecimento da propriedade privada dos meios de produção (o que pressupõe em primeira instância pensar a apropriação da natureza), o capital e o trabalho.

Ainda segundo Marx (2004), a história da natureza e da relação sociedade-natureza corresponde à história dos múltiplos e incessantes processos de apropriação da natureza natural pelo "homem", que ao redefinir usos, produziu expropriações da terra, concentração de capital, apropriação da força de trabalho humana, ao mesmo tempo em que reproduziu a desigualdade na distribuição dos recursos. Portanto, a história da natureza nada mais seria do que a história da divisão social e territorial do trabalho, construída no âmbito das relações humanas, ao longo do tempo histórico. Em outros termos, a produção da relação sociedade-natureza pressuporia pensar a um só tempo, o trabalho dos homens sobre a natureza e o trabalho dos homens sobre e para usufruto de outros "homens" (MARX; ENGELS, 2007).

Marx (2007) ressalta ainda que homem e natureza constituem elementos indissociáveis, imanentes ao engendramento das relações humanas ao longo do modo capitalista de produção. Ainda para Marx, homem e sociedade são a um só tempo, "objeto sensível" e "atividade sensível", uma vez que o ser social enquanto produtor de ações transforma o real ao produzir relações entre si e com a natureza.

A abordagem marxista permite pensar, portanto, a natureza em seu caráter relacional e complexo. No plano geral, a natureza enquanto totalidade ontológica e ao mesmo tempo epistemológica possibilita compreender processos, mediações e contradições no âmbito das relações de produção. Por sua vez, a natureza concebida em sua particularidade é pensada como elemento inteligível e constructo sociohistórico, inerente a uma determinada 
formação econômica e social, que contribuiria significativamente para análises críticas relacionadas às ações humanas, na produção de processos de apropriação da natureza e reprodução de contradições nas relações de produção capitalista.

\section{A relação sociedade-natureza e o pensamento geográfico contemporâneo}

O marxismo exerceu influência significativa na construção do pensamento geográfico contemporâneo, sobretudo a partir dos anos de 1970, quando a sociedade capitalista inserese num período marcado por crises sistêmicas (crises políticas, sociais, econômicas e mesmo ambientais) relacionadas ao sociometabolismo do capital. No plano do campo acadêmico, as perspectivas explicativas na geografia, pautadas em matrizes positivistas e historicistas não apresentavam inteligibilidade para analisar as contradições, rupturas e transformações sociais, econômicas, políticas que afloravam. É dentro desse contexto que os estudos marxistas foram "retomados" enquanto nexos explicativos de base teórico-epistemológica para análise da realidade social. Ao seu modo, Harvey (1993) aduz que a "teoria marxista" pode ser entendida dialeticamente como compreendedora da produção de espaço-tempo atributos fundamentais da "natureza".

Quaini (1979) retoma as reflexões marxistas a respeito do método para investigar a realidade, seja enquanto perspectiva teórica seja enquanto contribuição críticoepistemológica à natureza da produção capitalista, suas implicações na produção da natureza e na reprodução desigual do espaço. Para Quaini (1979), o discurso acerca da suposta "missão civilizadora do capital" contribuiu para a naturalização da lógica capitalista pautada no consumo e na criação de novos valores de uso e de troca. Dentro dessas circunstâncias de racionalidade instrumental capitalista, a natureza se torna uma coisa para o homem, um objeto de utilidade e, ao mesmo tempo, um meio de produção.

A "revolução" permanente do capital é claramente contraposta às velhas relações entre o homem e a natureza, aos antigos limites do desenvolvimento, bem como à reprodução de "velhos" modos de vida (QUAINI, 1979). Por sua vez, a produção econômica do espaço se apresenta como finalidade do homem e a riqueza como finalidade da produção.

As manifestações e contradições que agitam o capitalismo, de um ponto de vista ecológico, dizem respeito ao descompasso entre a reprodução das forças produtivas desenvolvidas ao longo do processo de formação econômica e social de determinados territórios e a 
ampliação de antagonismos sociais que ocorrem como resultado da penetração e da produção capitalista nos diversos espaços.

Não obstante, Quaini afirma que as contradições da lógica de produção capitalista não constituem somente expressões da relação natureza-território, mas escondem às contradições sociais, socioterritoriais resultantes da redefinição das formas de uso do território, de apropriação da mais valia, bem como de processos de concentração de capital que tendem a aprofundar tais contradições.

Essa compreensão de Quani é reinterpretada por Peluso (2013), para quem os elementos do espaço são vistos pela ótica do trabalho e da produção, para os quais a Natureza é um suporte no período técnico-científico, e, "mediante a tecnociência, a natureza artificializada alcança seu estágio supremo, onde a natureza e o homem tornam-se reciprocramente hostis" (SANTOS, 1992, p.106). Suertegaray (2006, p.38) faz uma crítica à compreensão técnico-científica sobre natureza: “[...] pensar o ambiente [e a natureza] hoje é ir além do domínio técnico de intervenção, para, sem negá-lo, repensá-lo no âmbito de novas lógicas que se estruturam e dão suporte a uma visão de resgate do entendimento de espaço geográfico na sua unidade e nas suas diferentes variantes conceituais, na sua multiplicidade".

Ainda a esse respeito, Moreira (2004, p.23) afirma que "a natureza na geografia é um substrato e arsenal de recursos naturais úteis para fins de subsistência e sobrevivência dos homens em sociedade". Apesar da reflexão lato (de pensar a natureza em geografia) de Moreira (2004), em abordagens posteriores Moreira (2006; 2009) avança em suas reflexões ao afirmar que a relação homem-natureza (relação metabólica), necessita ser compreendida para além do paradigma de movimento físico da matéria, como um processo de incorporação recíproca na qual participam o inorgânico, o biológico e o humano, posto que a natureza se constitui sobretudo como história social.

Assim, a relação sociedade-natureza se dá por intermédio do trabalho, pois

Tudo é história na relação metabólica porque vem do ato do homem transformar a natureza em sociedade pelo trabalho (fala-se aqui de primeira e segunda natureza ou natureza natural e natureza socializada), que, ecologicamente, é antes de tudo um intercâmbio de força e matéria que se passa entre o homem e a natureza dentro da própria natureza, e socialmente, é o processo de transformação da história natural em história social, e vice-versa (MOREIRA, 2009, p.14).

Segundo Moreira (2004), o trabalho constitui processo universal que transforma a natureza para a satisfação das necessidades materiais de subsistência 
O trabalho é essa atividade de transformação da natureza em meios de subsistência e de produção de novos meios sempre repetidamente. E a paisagem humanizada é o resultado geográfico desse processo. Na geografia, a relação homem-meio é um movimento entendido como a busca da satisfação das necessidades materiais de subsistência, e que é também o termo da sua realização (MOREIRA, 2004, p.29) [negritos nossos].

Esta afirmação de Moreira apresenta certa imprecisão na medida em que este autor, ao utilizar o termo "paisagem humanizada" abre precedentes para se pensar duas interpretações problemáticas: a primeira de uma natureza produzida e transformada pela ação humana, que Foster (2010, p.235) chama de "a natureza material existente" e, a segunda, de uma natureza subjugada pela ação humana, por isso humanizada. 0 estabelecimento desta ambiguidade pode promover uma compreensão equivocada quanto à análise marxista e ecológica (ou ecomarxista), segundo a qual o homem é parte da natureza e interdependente na sua relação com a mesma, sendo, portanto impossível subjulga-lá e ao mesmo tempo humanizá-la (FOSTER, 2010).

Compreender a relação sociedade-natureza dentro de uma perspectiva marxista pressupõe ver o trabalho como elemento imprescindível, como atividade vital (contribuidor para hominização), como meio para satisfação de necessidades de manutenção da existência (MARX, 2004). A vida física e mental do homem encontra-se, portanto, interconectada com a natureza, ao mesmo tempo em que a natureza está interconectada consigo mesma, pois o homem é uma parte da natureza (MARX, 2004).

Com efeito, a relação sociedade-natureza necessita ser compreendida enquanto totalidade múltipla, processual, seja como nexo explicativo que possibilite analisar as imbricações, os significados, as contradições e ambivalências inerentes às relações capitalistas de produção, seja enquanto práxis social que se realiza e se reproduz a partir de dinâmicas diversas, de movimentos perpétuos de transformação do presente, do passado e do devir, enquanto possibilidade necessária para a construção de uma outra epistemologia, que permita pensar as "fraturas", as "bifurcações", as contra-hegemonias, mas também a complexidade e diversidade do real em realização. 


\section{CONSIDERAÇÕES FINAIS}

Refletir criticamente a respeito do processo de ressignificação dos conceitos e debates sobre a relação sociedade-natureza não constitui tarefa das mais fáceis, sobretudo pela diversidade de interpretações discordantes entre os mais variados campos científicos. Nesse sentido, convém advertir para o caráter ensaístico e mesmo embrionário das reflexões apresentadas. "Revisitar" as respectivas matrizes de pensamento (Kant, Hegel, Marx, por exemplo) acerca da relação sociedade-natureza constitui ponto de partida relevante para se refletir criticamente não apenas sobre o objeto da ciência geográfica (relação sociedadeespaço), mas também sobre a formação do pensamento científico no período contemporâneo, construído a partir de perspectivas que se movimentam e se projetam nos planos das universalidades, particularidades e singularidades.

As perspectivas universalizantes que outrora se apresentavam como resultado de uma herança positivista (pautada em um saber sistemático, hierárquico, homogeneizador) no período atual, projetam-se e engendram-se estrategicamente como condição e resultado de ações, de relações, de intencionalidades; que objetivam a construção de um pensamento geral, e a constituição de um saber científico hegemônico que tende a "alijar" a possibilidade de construção de um conhecimento aberto, dinâmico, dialético. Ainda nesse sentido, o juízo de autoridade de muitas das concepções gerais que se "forjam" como elementos explicativos, tendem a negar singularidades relacionadas às condições de engendramento e realização da sociedade-natureza nos lugares, negando assim a possibilidade de se pensar a natureza da natureza e sua realização específica.

Elemento emblemático da reprodução desse pensamento geral pode ser evidenciado na construção de uma série de pesquisas no Brasil que tendem a fazer uma espécie de "transplante" de conceitos e categorias concebidos no campo acadêmico de universidades européias, que são trazidas para analisar as realidades brasileiras sem considerar as particularidades e singularidades regionais e locais.

Nas particularidades imanentes ao movimento de transformação e ressignificação do termo natureza em geografia, encontra-se a potencialidade explicativa para análises a respeito da relação sociedade-natureza, à medida que este plano de compreensão da realidade manifesta-se como possibilidade para entender fatos, ideias, ações, relações, ligações, fenômenos, discursos que se constituem como meio e resultado do processo de transformação da realidade. 
O encontro e o confronto entre universalidades e singularidades, bem como o "choque epistêmico" entre antigas e novas perspectivas de pensamento buscam, de um lado, conceber "artifícios interpretativos" para aplicá-lo ao real; e de outro, analisar a diversidade do real em suas múltiplas e complexas determinações, estabelecidas ao longo do espaçotempo e do movimento relacional entre historicidade e práxis.

Nesse contexto de embates acadêmico-políticos, de "choques epistêmicos" entre perspectivas de ler a realidade, aflora e acentua-se um conjunto de pensamentos em defesa da fragmentação do saber geográfico e de estímulo à dicotomia na construção de um pensamento geográfico, pautada na separação entre a geografia humana e a geografia física. Tais perspectivas decorrem, em grande medida, de leituras simplificadoras pautadas em concepções fragmentadas e fragmentadoras de análise da realidade, que tendem a conceber ciência e realidade social como instâncias separadas, fronteiras rígidas do conhecimento que buscam analisar particularidades e singularidades sem considerar suas relações com as universalidades, com os movimentos da complexidade recambiante, da ordem e da desordem, do equilíbrio e do desequilíbrio que compõem e expressam a natureza e a relação sociedade-natureza.

Como resultado, muitas perspectivas na geografia vem concebendo e reproduzindo uma realidade como compartimentos, por vezes fechados, sem estabelecer as devidas relações, ligações e conexões com outras instâncias e dimensões disciplinares, que podem apresentar determinações processuais significativas para a compreensão da realidade.

Em última instância, a separação entre a geografia humana e geografia física constitui resultado da construção da hegemonia da "disciplinaridade fechada" no campo acadêmico, que tende a reforçar a fragmentação das ciências e a construção de concepções limitadoras, a partir de leituras reducionistas que interpretam singularidades desconectadas e desconexas, como verdadeiras "ilhas epistemológicas" (JAPIASSU, 2006). Portanto, não inteligíveis à explicação da realidade e suas múltiplas e complexas transformações: políticas, econômicas, sociais, territoriais, espaciais e ambientais no Mundo, nos Brasis, nas Amazônias.

As reflexões apresentadas reforçam a necessidade de se pensar a natureza (relação sociedade-natureza) enquanto totalidade em movimento relacional, como elemento complexo e diverso, elo indissociável que permite compreender, de maneira integrada, articulada, universalidades, particularidades e singularidades, planos de análises necessários para compreender a produção da realidade, os processos de apropriação, os usos no âmbito 
do engendramento de lógicas capitalistas de produção, bem como de intencionalidades presentes nos discursos hegemônicos e contra-hegemônicos acerca da produção da natureza e da natureza em produção permanente, perpétua.

Considerando os diálogos e as reflexões acerca da fragmentação do pensamento científico geográfico, algumas questões parecem emergir para efeito de outras investigações, quais sejam: O pensamento geográfico, ao privilegiar uma perspectiva de construção do conhecimento pautado na fragmentação do saber, não estaria construindo um pensamento restrito, limitado e superficial acerca da realidade, fato que tem resultado na dificuldade de se compreender o real em suas múltiplas, diversas e complexas determinações? O processo de fragmentação do conhecimento científico estaria caminhando rumo à construção de um "instinto formativo" ou tão somente servindo para o fortalecimento de um "instinto conservativo", nos termos de Bachelard (1997)? O processo de fragmentação do conhecimento geográfico e de criação de novas subáreas vem contribuindo para o fortalecimento da ciência geográfica ou para a sua "autodestruição", enquanto domínio do saber científico que possibilita analisar articuladamente espacialidades, complexidades e diversidades processuais que se realizam no período contemporâneo? O que fazer diante da crise do pensamento científico geográfico e da limitada capacidade de produzir conhecimentos que permitam compreender em suas articulações, interações e contradições, as múltiplas, diversas, complexas transformações, fenômenos, processos globais, regionais e locais que se manifestam no período contemporâneo?

As indagações levantadas constituem ponto de partida para se pensar ou repensar as ciências em geral, e a ciência geográfica em particular, enquanto possibilidade para a construção de outra epistemologia, marcada pela superação do pensamento fragmentador (hipercartesianismo), que tende ao "amordaçamento" explicativo da realidade, a um pensamento "acrítico" concernente à relação sociedade-natureza em sua complexidade e diversidade.

\section{REFERÊNCIAS BIBLIOGRÁFICAS}

ANTUNES, J. Hegel e os fundamentos geográficos da história - o clima e o solo como condicionantes de progresso ou atraso histórico. Tempo da Ciência, v.12, n.24, p.61-71, 2005. 
ARENDT, H. Lectures on Kant's political philosophy. Chicago: The University of Chicago Press, 1992.

BACHELARD, G. A formação do espírito científico: contribuição para uma psicanálise do conhecimento. Rio de Janeiro: Contraponto, 1996.

BORNHEIM, G. Os filósofos Pré-Socráticos. São Paulo, Cultrix, 1985.

CHATELET, F. Hegel e a geografia. Geosul, v.4, n.7, p.45-62, 1989.

DUDLEY, W. Hegel and history. New York: State University of New York Press, 2009.

ELDEN, S. Reassessing Kant's geography. Journal of Historical Geography, n.35, p.3-25 2009.

FOLADORI, G. A questão ambiental em Marx. Crítica Marxista, n.4, p.140-161, 1997.

FOSTER, J. B. A Ecologia de Marx: materialismo e natureza. 2. ed. Rio de Janeiro: Civilização Brasileira, 2010.

FOSTER, J. B. The communist manifesto and the environment. The Socialist Register, v.34, p.169-189, 1998.

FOSTER, J. B.; BURKETT, P. The dialectic of organic/inorganic relations: Marx and the Hegelian philosophy of nature. Organization \& Environment, v.13, n.4, p.403-425, 2000.

HARVEY, D. The nature of environment: the dialectics of social and environmental change. The Socialist Register, v.29, p.1-51, 1993.

HEGEL, G. W. F. Lezioni sulla filosofia della storia. Firenze: La nuova Italia, 1961.

HEGEL, G. W. F. Ciencia de la lógica. 5a ed. Buenos Aires: Ediciones Solar, 1982.

HEGEL, G. W. F. Fenomenologia do Espírito. 2a ed. Petrópolis: Vozes, 1992.

HEGEL, G. W. F. A Razão na História: Introdução à Filosofia da História Universal. Lisboa: Edições 70, 1995.

HEGEL, G. W. F. A Razão na historia: uma introdução geral a filosofia da historia. 2a ed. São Paulo: Centauro, 2001. 
JAPIASSU, H. O sonho transdisciplinar e as razões da filosofia. Rio de Janeiro: Imago, 2006.

KANT, I. Crítica da razão pura. Lisboa: Fundação Calouste Gulbenkian, 1982.

KANT, I. Primeiros princípios metafísicos da ciência da natureza. Lisboa: Edições 70, 1990.

KANT, I. Géographie. Paris: Aubier, 1999.

KANT, I. Critique of the power of judgment. New York: Cambridge University Press, 2000.

LIVINGSTONE, D. N.; HARRISON, R. T. Immanuel Kant, Subjectivism, and human geography: a preliminary investigation. Transactions of the Institute of British Geographers, v. 6, n. 3, p. 359-374, 1981.

LUTHER, T. C. Hegel's Critique of Modernity: reconciling individual freedom and the community. New Yok: Lexington Books, 2009.

MARX, K. Manuscritos econômico-filosóficos. São Paulo: Boitempo, 2004.

MARX, K. Contribuição para a crítica da filosofia do Direito em Hegel. 2a ed. São Paulo: Boitempo, 2010.

MARX, K. Grundrisse. São Paulo: Boitempo, 2011.

MARX, K.; ENGELS, F. A ideologia alemã. São Paulo: Boitempo, 2007.

MOREIRA, R. Política e técnica neste final de século. Boletim Goiano de Geografia, v.12, n.1, p.29-44, 1992.

MOREIRA, R. Modelo industrial e meio ambiente no espaço brasileiro. GEOgraphia, Ano 5, n.9, p.7-28, 2003.

MOREIRA, R. Marxismo e geografia (a geograficidade e o diálogo das ontologias). GEOgraphia, Ano 6, n.11, p.21-37, 2004.

MOREIRA, R. Para onde vai o pensamento geográfico. São Paulo: Contexto, 2006.

MOREIRA, R. A geografia e a educação ambiental: o modo de ver e pensar a relação ambiental na geografia. Espaço em Revista, v. 11, n.1, p.11-19, 2009. 
MOREIRA, R. Correndo atrás do prejuízo o problema do paradigma geográfico da geografia.

Revista da ANPEGE, v. 7, n. 1, número especial, p.50-58, 2011.

MORIN, E. A necessidade de um pensamento complexo. In: MENDES, Candido (Org.). Representação e complexidade. Rio de Janeiro: Garamond, 2003.

MORIN, E. O futuro caminha para o passado. Tempo, v.1, p.15- 20. 1996.

MORIN, E. O método 1: a natureza da natureza. 2ª ed. Porto Alegre: Sulina, 2008.

OLIVEIRA, A. M. S. Relação Homem - Natureza no modo de produção capitalista. Scripta Nova - Revista Eletrónica de Geografia y Ciencias Sociales, v.6, n.119, p.1-8, 2002.

PELUSO, M. L. O desafio de compreender a natureza na obra de Milton Santos. Revista Eletrônica: Tempo - Técnica - Território, v.4, n.1 p.21-28, 2013.

PEREIRA, M. F. R. A geografia no pensamento filosófico. Mercator, v.5, n.10, p.31-37, 2006.

PORTO-GONÇALVES, C. W. El Desafío Ambiental. Ciudad de Mexico: PNUMA, 2006a.

PORTO-GONÇALVES, C. W. A globalização da natureza e a natureza da globalização. Rio de Janeiro: Civilização Brasileira. 2006b.

PORTO-GONÇALVES, C. W. Os (des)caminhos do meio ambiente. 15a ed. São Paulo: Contexto, 2011.

QUAINI, M. Marxismo e geografia. Rio de Janeiro: Paz e Terra, 1979.

QUENTIN, B. Hegel et la matière : le philosophe allemand a-t-il encore quelque chose à nous dire?. Les études philosophiques, v.4, n.79, p.537-556, 2006.

RANGEL JUNIOR, V. M. As Artes do Daimon: à procura de uma poética perdida. 412f. Tese (Doutorado em Ciência da Literatura) - Programa de Pós-Graduação em Letras, Universidade Federal do Rio de Janeiro, Rio de Janeiro, 2006.

SANGUIN, A. L. Redécouvrir la pensée géographique de Kant. Annales de Géographie, ano 103, n.576, p.134-151, 1994.

SANTOS, M. 1992: a redescoberta da Natureza. Estudos Avançados, v.6, n.14, p.95-106, 1992. 
SANTOS, M. A questão do meio ambiente: desafios para a construção de uma perspectiva transdisciplinar. Anales de Geograjía de la Universidad Complutense, n.15, p.695-705, 1995.

SANTOS, M. A natureza do Espaço. Técnica e Tempo. Razão e Emoção. 1a ed. São Paulo: Hucitec, 1996.

SANTOS, M. Por uma gepografia nova: da crítica da geografia a uma geografia crítica. 6a ed. São Paulo: EDUSP, 2004.

SOUZA, B. I.; SUERTEGARAY, D. M. A. Considerações sobre a geografia e o ambiente. Okara: Geografia em Debate (UFPB), v.1, n1, p. 5-15, 2007.

SUERTEGARAY, D. M. A. Um antigo debate (a divisão e a unidade da geografia) ainda atual?. Boletim Paulista de Geografia, v.85, p.29-38, 2006.

VITTE, A. C. A terceira crítica kantiana e sua influência no moderno conceito de geografia física. Geousp (USP), v.19, p.33-56, 2006a.

VITTE, A. C. Metafísica, natureza e geografia: apontamentos para o debate sobre a geografia física moderna. Boletim Paulista de Geografia, v.85, p.7-27, 2006b.

VITTE, A. C. A ciência geográfica: entre a crise da razão e a reconstrução do cosmos. Geografia em Atos, n.7, v.1, p.1-11, 2007a.

VITTE, A. C. Da metafísica da natureza à gênese da geografia física moderna. In: VITTE, A. C. (Org.). Contribuições à história e à epistemologia da geografia. Rio de Janeiro: Bertrand Brasil, 2007b. p.11-47.

VITTE, A. C. Influências da filosofia kantiana na gênese da geografia física. Mercator, v.7, p.57-66, 2008

VITTE, A. C.; SILVERIA, R. W. D. da. A filosofia kantiana e a construção das ciências da natureza: os fundamentos da geografia física moderna. Terr@ plural, v.3, p.103-116, 2009.

VITTE, A. C.; SPRINGER, K. S. A geografia, a natureza e o impasse da modernidade: o romantismo e as possibilidades interpretativas para a questão ambiental. Revista da Casa da Geografia de Sobral, v.1, p.1-16, 2010. 
Artigo recebido em 28/08/2013.

Artigo aceito em 14/01/2014. 